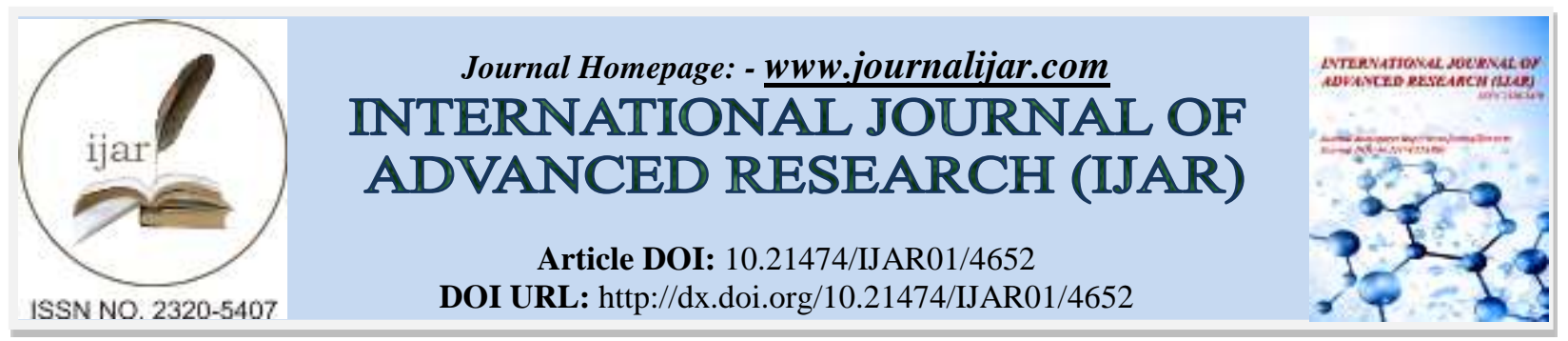

RESEARCH ARTICLE

\title{
A NEW VARIANT OF UNILATERAL TRANSMIGRATED CANINES: A CASE REPORT.
}

\section{Dr Puneet Wadhwani MDS ${ }^{1}$, Dr Ramesh Ram Fry ${ }^{2}$, Dr Himanshu Chauhan MDS ${ }^{3}$, Dr Arpita Komal ${ }^{4}$, Dr Shamita Tiwari ${ }^{4}$ and Dr Amartya Prakash Srivastava ${ }^{4}$.}

1. Professor, Dept of Oral and Maxillofacial Surgery Saraswati Dental College, Lucknow (UP).

2. Professor, Dept of Oral and Maxillofacial Surgery, MM College of Dental College and Research, Ambala, Haryana

3. Senior Lecturer, Dept of Oral and Maxillofacial Surgery, Saraswati Dental College, Lucknow (UP).

4. Post Graduate student, Dept of Oral and Maxillofacial Surgery, Saraswati Dental College, Lucknow (UP).

\section{Manuscript Info}

Manuscript History

Received: 25 April 2017

Final Accepted: 28 May 2017

Published: June 2017

Key words:-

Canine, Transmigration, Impacted tooth.

\section{Abstract}

Transmigration of a tooth is a rare, infrequent usually symptomless eruptive disorder and is defined as the phenomenon of an unerupted tooth crossing the midline or when more than half of the impacted tooth has migrated across the midline. The exact etiology of the disorder still remains obscure, varied mechanical and biological factors as an etiology have been proposed over the years.

This condition usually affects maxillary and mandibular cuspids with various classifications projected in the literature, in this article we report a new variant of unilateral transmigration of canine in the mandibular arch which has not been documented till date.

Copy Right, IJAR, 2017,. All rights reserved.

\section{Introduction:-}

Permanent teeth which do not erupt for more than a year after the normal age of eruption are known as impacted or retained. An even rarer phenomenon reported in the literature is the crossing of midline of impacted tooth/teeth to the other side of the arch. Several terms have been used for this phenomenon such as anomalous, mal-positioned or displaced tooth. However, the term transmigration was coined by Ando et al in $1964^{5}$.

Tarsitano et al defined transmigration as a phenomenon in which an unerupted mandibular canine migrates, crossing the mandibular midline. Javid modified Tarsitano's definition, adding, that at least one half or more of the length of the tooth is required to cross the midline ${ }^{9}$.

The transmigrated teeth were classified by M Mupparapu (2002) into Types 1 to 5 based on their migratory pattern and their final position within the jaw when diagnosed ${ }^{7}$.

Type 1- canine positioned mesioangularly across the midline within the jaw bone, labial or lingual to anterior teeth, and the crown portion of the tooth crossing the midline.

Type 2- canine horizontally impacted near the inferior border of the mandible below the apices of the incisors.

Type 3- canine eruption either mesial or distal to the opposite canine.

Type 4 - canine horizontally impacted near the inferior border of the mandible below the apices of either premolars or molars on the opposite side. 
Type 5- canine positioned vertically in the midline(the long axis of the tooth crossing the midline) irrespective of eruption status.

Qaradaghi proposed one more type to this classification that is the Type 6 which is defined as parallel migration of both canines at the same rate to the contra lateral sides ${ }^{11}$.

However in 2007, M Mupparapu proposed a separate classification for bilateral transmigrated canines and Qaradaghi's case could now be classified a Type III Subtype $\mathrm{B}^{8}$.

We propose another variant to this classification which has not been reported so far in the literature.

\section{Case Report:-}

A 27 year old female patient reported to our department with the chief complaint of pain in the lower premolar region. Clinical examination revealed retained deciduous canine on both sides of the mandibular arch. No shifting of midline was noted.

Panoramic radiograph revealed impacted mandibular right and left canines. However, the right canine not only crossed the midline but also "Crossing over" the existing impacted left canine was evident. Cone beam computed tomography (CBCT) was done and it was noted that the transmigrated canine also brought about changes in the morphology of the inferior alveolar canal of the left side. Bony changes were also seen at the coronal aspect of the transmigrated canine.

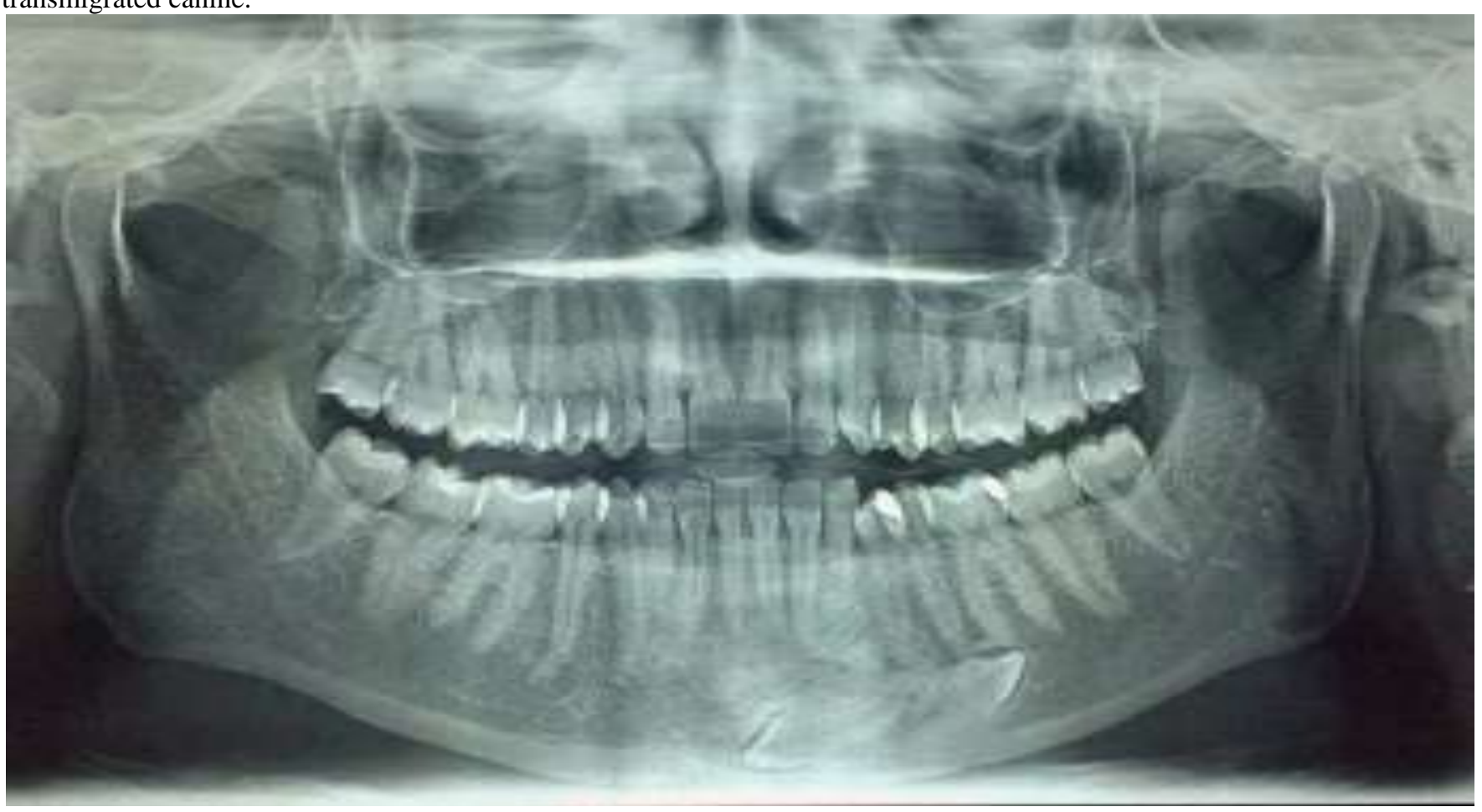

Figure 1:- Orthopantamogram showing the transmigrated canine. 


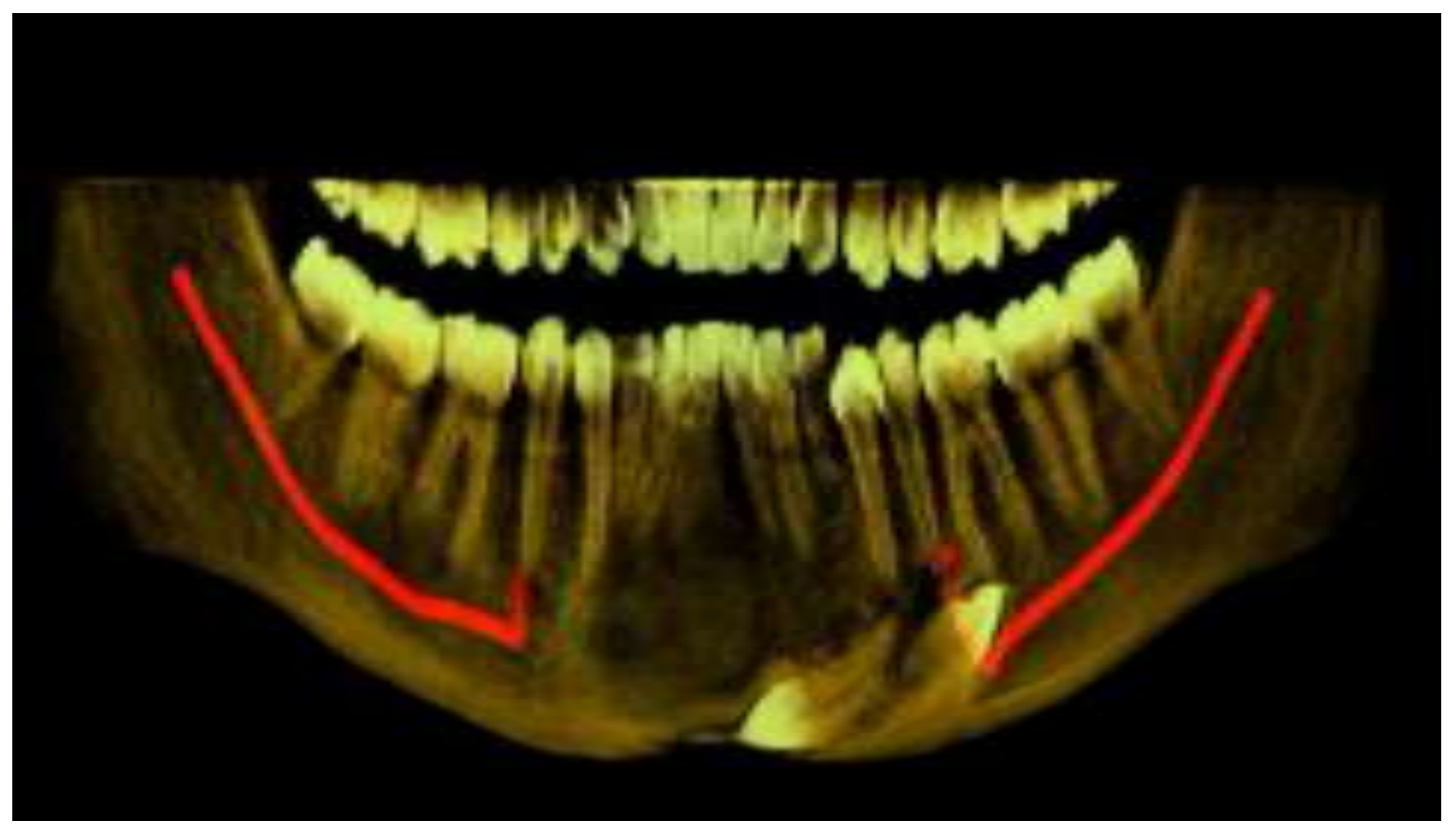

Figure 2:- CBCT image (labial aspect) showing the transmigrated canine, bone changes above the canine and change in morphology of the left inferior alveolar canal.

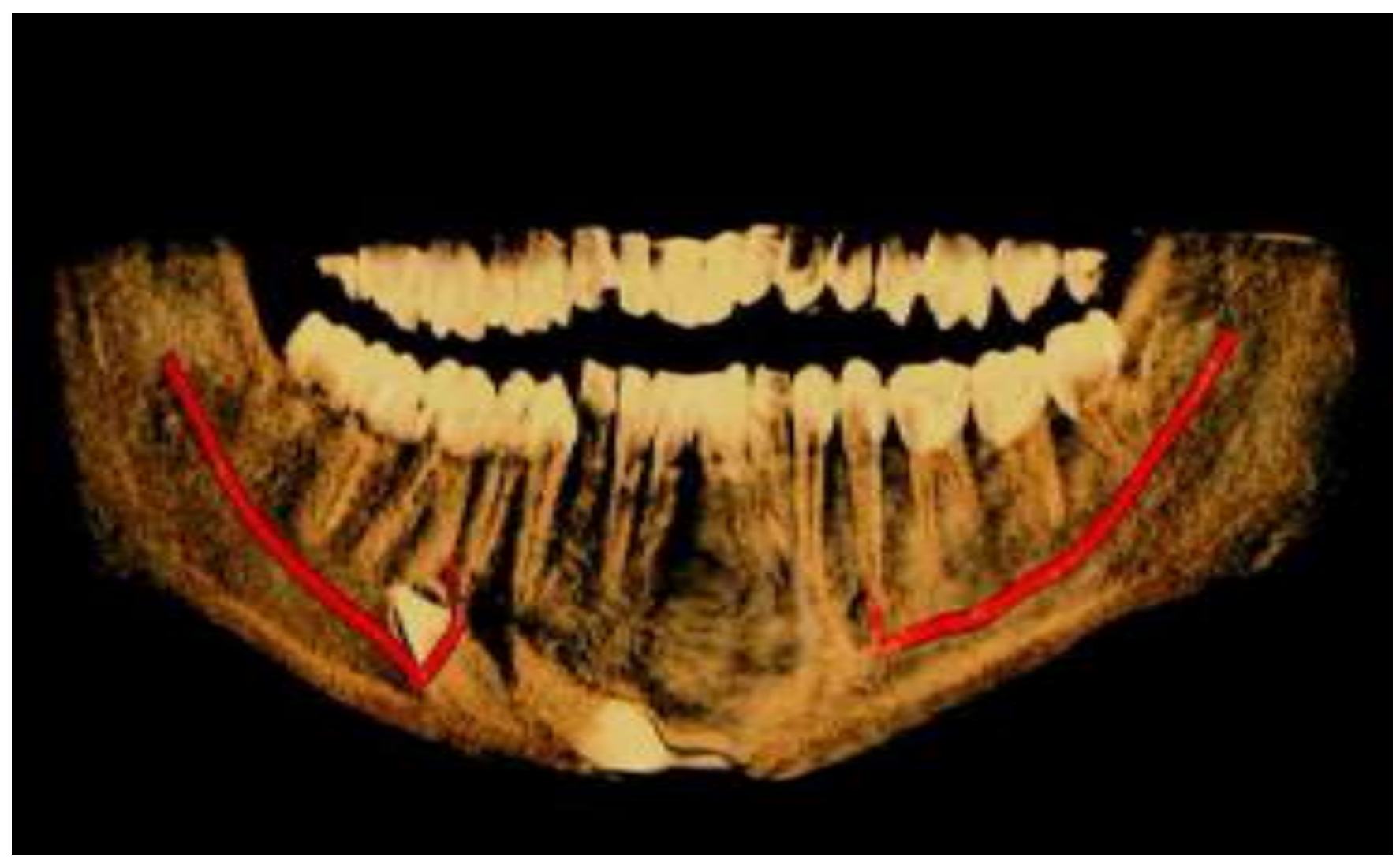

Figure 3:- CBCT image (lingual aspect) showing the transmigrated canine. 


\section{Discussion:-}

Though canine impaction is more prevalent in maxilla, transmigration of impacted canine has been more commonly found in mandible 9 . The finding is generally unilateral with left side being more commonly involved than the right $\operatorname{side}^{13}$. Incidences are more commonly seen in females than males in a ratio of $1.6: 1^{10}$. In most of the reports of transmigrated teeth they were found in a horizontal position, below the apices of the erupted teeth. Aydin and Yilmaz were the first to publish a case report of a maxillary transmigrated canine ${ }^{2}$. Transmigration of an impacted maxillary canine is a very rare condition. This may be attributed to the fact that there is less space between the apices of the maxillary canine and floor of the nasal fossa, and to the presence of the midpalatal suture which is a considerable barrier against maxillary canine migration ${ }^{2}$.

There is no specific etiology for occurrence of transmigration however, some factors which have been attributed to its existence may be classified as local and systemic. The local factors include traumatic factors, the long eruption path of canine tooth germs, ectopic growth of the tooth bud, retention or premature loss of a primary tooth, inadequate eruption space and odontomas ${ }^{3}$. Systemic factors associated with it are genetic factors and endocrine disorders.

Transmigrated teeth are revealed by clinical and radiographic examinations. They usually remain asymptomatic or may cause pressure resorption of roots or tilting of adjacent teeth. Like any other impacted tooth, transmigrated teeth also have increased chances of acting as foci of cyst, tumors or infection ${ }^{1,14}$.

Treatment options include surgical removal, transplantation and surgical exposure with orthodontic alignment. Surgical extraction is the treatment of choice. If the patient is symptomatic with associated abnormalities like apical cyst, neuralgia, resorption of an adjacent tooth root or displacement of teeth then surgical extraction should be planned immediately ${ }^{2,4,6,12}$.

An important point to note is that even though the tooth has transmigrated to the contralateral side, it maintains its nerve connection to the originating site $^{7}$. Therefore, it is important to anesthetize the nerve on the originating site during surgical intervention.

However, if the tooth lies in close proximity to the nerve canal and the patient is asymptomatic then the tooth can be left in place but regular follow up with radiograph is necessary to monitor movement of these teeth.

\section{Conclusion:-}

Till the time of this article going to press, around 200 transmigrated canine cases have been documented and reported in literature. Separate classification of unilateral and bilateral transmigrated canines' leaves scope for further modifications.

\section{References:-}

1. Auluck A, Nagpal A, Setty S, Pai K, Sunny J. Transmigration of impacted mandibular canines; Report of 4 cases. J can dent assoc. 2006; 72: 249-52.

2. Aydin U, Yilmaz H. Transmigration of impacted canines. Dentomaxillofacial Rdiology 2003; 32: $198-200$.

3. Aydin U, Yilamz H, Yildirim D. Incidence of canine impaction and transmigration in a patient population. Dentomaxilofacial Radiology. 2004; 33:164-9.

4. Bishara, S.E. Impacted maxillary canines: A review. American J Ortodont Dentofac Orthhoped. 1992;101(2):159-71.

5. Camilleri S, Scerri E. Transmigration of mandibular canines : A review of the literature and a report of 5 cases. Angle orthod 2003; 73, 753-62.

6. Mazinis E, Zafeiriadis A, Karathanasis A, Lambrianidis T. Transmigration of impacted canines; Prevalence, management and implications on tooth structure and pulp vitality of adjacent teeth. Clin oral investing. 2012;16: 625-32.

7. M Mupparapu : Patterns of intraosseous transmigration and ectopic eruption of mandibular canines. Dentomaxillofacial Radiology 2002, 31, 355-360.

8. M Mupparapu : Patterns of intraosseous transmigration and ectopic eruption of bilaterally transmigrating mandibular canines : Radiographic study and proposed classification. Quintessence Int 2007; 38: 821-828 
9. N Watted, E Hussein, O Awadi, M Abu Hussein : Transmigration of impacted canines : A report of two cases and a review of literature. J of Dental Sciences 2014; 2(4): 23-32.

10. Peck S. On the phenomenon of intraosseous migration of non erupting teeth. Am J Orthod Dentofacial Orthop 1998; 113: 515-7.

11. Qaradaghi : First case of bimaxillary transmigration of impacted canines : Report of rare case and review of literature : Archives of oral research, jan/apr 2012 v.8, n.1, p.77-80.

12. Shanmuhasuntharam P, Boon LC. Transmigration of permanent mandibular canines. Case report. Aust dent J. 1991; 36(3) : 209-13.

13. Shapira Y, Kuftinec MM. Intrabony migration of impacted teeth. Angle Orthod 2003; 73: 738-43.

14. Tarsitano J, Wooten J, Burditt J. Transmigration of non-erupted mandibular canines : Report of cases. The $\mathbf{J}$ American Dent Assoc 1971; 82(6) : 1395-7. 